$$
\begin{aligned}
& \text { LAtmospheric methane researih prog pam } \\
& \text { For a situdy in }[\text { hing }] \text { DOE/ER/60313--5 }
\end{aligned}
$$

contents:

DE9 1005573

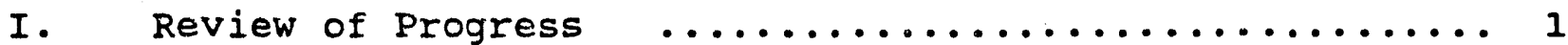

II. Program for the coming Year.................... 4

III. Budget ............................... 14

IV. Attachments: Atmospheric Methane:

Recent Global Trends ...................... 16

\title{
I. Review of Progress:
}

The most significant results of recent research are the findings

(1) that methane emissions from rice paddies are strongly dependent on the soil temperature, and (2) that the fluxes of methane from the chinese rice paddies are up to 10 times greater on average compared with fluxes from rice paddies in other parts of the world. In addition to these main findings there are a number of other significant results. These are: (1) the extension of a time series of concentrations of methane (and also of other gases) at Mingin. The data now span sufficiently long times to estimate trends and seasonal variations and to include Minqin in our global flask sampling network. (2) We have completed further work on bio-gas pits. (3) We have also measured methane in Beijing and found relatively low concentrations for an urban area.

We summarize these results in the figures that follow. We want to stress that the results described here are preliminary and subject to change upon final interpretation after the data have been reanalyzed and researched.

(1) Figure 1 shows the effect of temperature on the estimated flux of methane based on more than 400 calcuiated valuas of the flux. Because of the large variaility of the fluxes, even at the same temperature, we have plotted both the normal average estimates of concentrations and the median values of the flux. Both measures 
suggest the sharp increase of flux vith temperature. The increase is almost 10 fold over a temperature range of only 15 degrees $c$. At the warmest temperatures there appears to be a downturn in the flux which can also be explained as past the optimum temperatures for biological productivity. At present we are looking at the various factors, other than temperature, that may also be related to the increasing flux.

(2) Figure 2 shows the fluxes of methane from the chinese rice paddies in arbitrary units. When converted to mass flux, the median flux is 5-12 times the fluxes reported in the literature from rice paddies in other parts of the world. The high flux is most likely related to the unique agricultural practices in china. The variability of the flux is also noteworthy. The range of observed fluxes is two orders of magnitude. Some of the variation is due to the temperature effect mentioned above. This effect will be subtracted to look at the nature of the distribution of the observed fluxes. At present it is difficult to extrapolate these findings into a regional flux estimate for all of china.

of the other significant results mentioned above the most important is the current data base at Mingin in Gansu Province.

(1) The data at Minqin are long enough to see the usual features of methane at non-urban locations. We have plotted the results in several ways to obtain a perspective of the concentrations of methane at Mingin. In Figure 3 we show the global view. The annual average data are shown in contrast to the average data from our long-term flask samp'ing sites (Barrow, Alaska; Cape Meares, oregon; Mauna Loa and Cape Kumukahi, Hawaii; Samoa; Cape Grim, Tasmania; and the south pole). The average concentration at Minqin is compatible but somewhat higher than would be expected from an interpolation of the background sites. This is probably due to regional scale pollution effects. The other sites are extremely remote by comparison to Minqin and are also mostly 
influenced by oceanic air masses.

The time series are shown in Figures 4 and 5 . In Figure 4 we show the monthly average concentrations at comparable northern hemisphere locations and the contrast of the length of measurements at Mingin and the other sites. In Figure 5 we show a smoothed version of the data at Mingin and the same northern hemisphere sites shown in Figure 4 over the past two years or so. The results show once again that the concentrations are higher than expected for the latitude of Mingin. The results also show that the rate of increase at Mingin is about $2 \%$ per year which is substantially higher than the long-term global rate of increase. Such an occurrence, however, is common for short data records. Previous experience has shown that records of up to two years can show substantially different rates of increase for methane compared to the longer-term rates of increase (see attachment, M.A.K. Khalil and R.A.Rasmussen "Atmospheric Methane: Recent Global Trends" - OGC preprint - submitted for publication).

The seasonal variations are shown in Figure 6 . The cycle repeats but there are occasional anomalies such as in May of 1986. Generally the concentrations are lower in the summer and higher in winters as expected from the cycle of hydroxyl radicals that remove methane from the atmosphere.

(2) The continuation of the studies of bio-gas pits shows that the leakage from the ballast tanks is considerably more than from the plug on top (Figure 7). Still the extrapolation of these fluxes does not make a big source ( $\leq 1 \mathrm{Tg} / \mathrm{yr}$ out of a global budget of some $500 \mathrm{Tg} / \mathrm{yr}$ ). This experiment is not yet complete so that we are still unable to say with confidence that the bio-gas pits are not a significant source of atmospheric methane (see section on proposed experiments). 
(3) Finally we have included a graph (Figure 8) of the concentrations of methane at Beijing. It shows that the urban areas of China, like urban areas in other parts of the world, are a source of methane. However, Chinese cities do not appear to have much higher concentrations of methane compared to other cities. This is probably due in part to the fewer cars in Beijing compared to European and American cities.

\section{Program For the coming Year:}

our plan for work during the next year remains similar to the original proposal. There are five main components:

(1) Rice Paddy Fluxes: We want to continue the studies of the rice paddy fluxes. The experimental procedures are working well and we need to continue to apply them for additional data at another site to assess the possible variability of emissions based on different agricultural practices and climatic conditions.

(2) Studies of Mass Balance of Global Methane: significant progress has been made already on modeling the global mass balance of methane in the atmosphere. The work is continuing. We are particularly interested in making an assessment of how much effect China has on the global budget.

(3) Inter-calibration: We plan to carry out a field intercomparison of methane fluxes from rice paddies. This exercise will be conducted with $w$. Seiler who has been taking measurements of methane fluxes in Hangzhou. The results of this exercise will be useful in determining the accuracy of the measurement methods. This work will be tied to the first objective mentioned above. It will give us the opportunity to obtain more field measurements of methane fluxes. 
(4) Bio-gas Pits: While present results do not show bio-gas pits to be substantial sources of methane, we still have more experiments to do before we can be sure about their role in the global and regional methane budgets. Most of uur measurements have been taken during cool periods in chendu. The production of methane in bio-gas pits is likely to be strongly temperaturedependent as suggested by the rice paddy data discussed above and shown in Figure 1. If this is so, we need to measure fluxes from the ballast tanks and other leakages of methane during the summers. Moreover, similar measurements need to be taken at lower and much warmer latitudes where methane production in bio-gas pits is significantly higher. When these data are in, we will be able to conclude the analysis of the methane fluxes from bio-gas pits.

(5) Background Site: The work at Mingin will continue as before.

\section{DISCLAIMER}

This report was prepared as an account of work sponsored by an agency of the United States Government. Neither the United States Gnvernment nor any agency thereof, nor any of their employees, makes any warranty, express or implied, or assumes any legal liability or responsibility for the accuracy, completeness, or usefulness of any information, apparatus, product, or process disclosed, or represents that its use would not infringe privately owned rights. Reference herein to any specific commercial product, process, or service by trade name, trademark, manufacturer, or otherwise does not necessarily constitute or imply its endorsement, recommendation, or favoring by the United States Government or any agency thereof. The views and opinions of authors expressed herein do not necessarily state or reflect those of the United States Government or any agency thereof. 
FIGLRE I

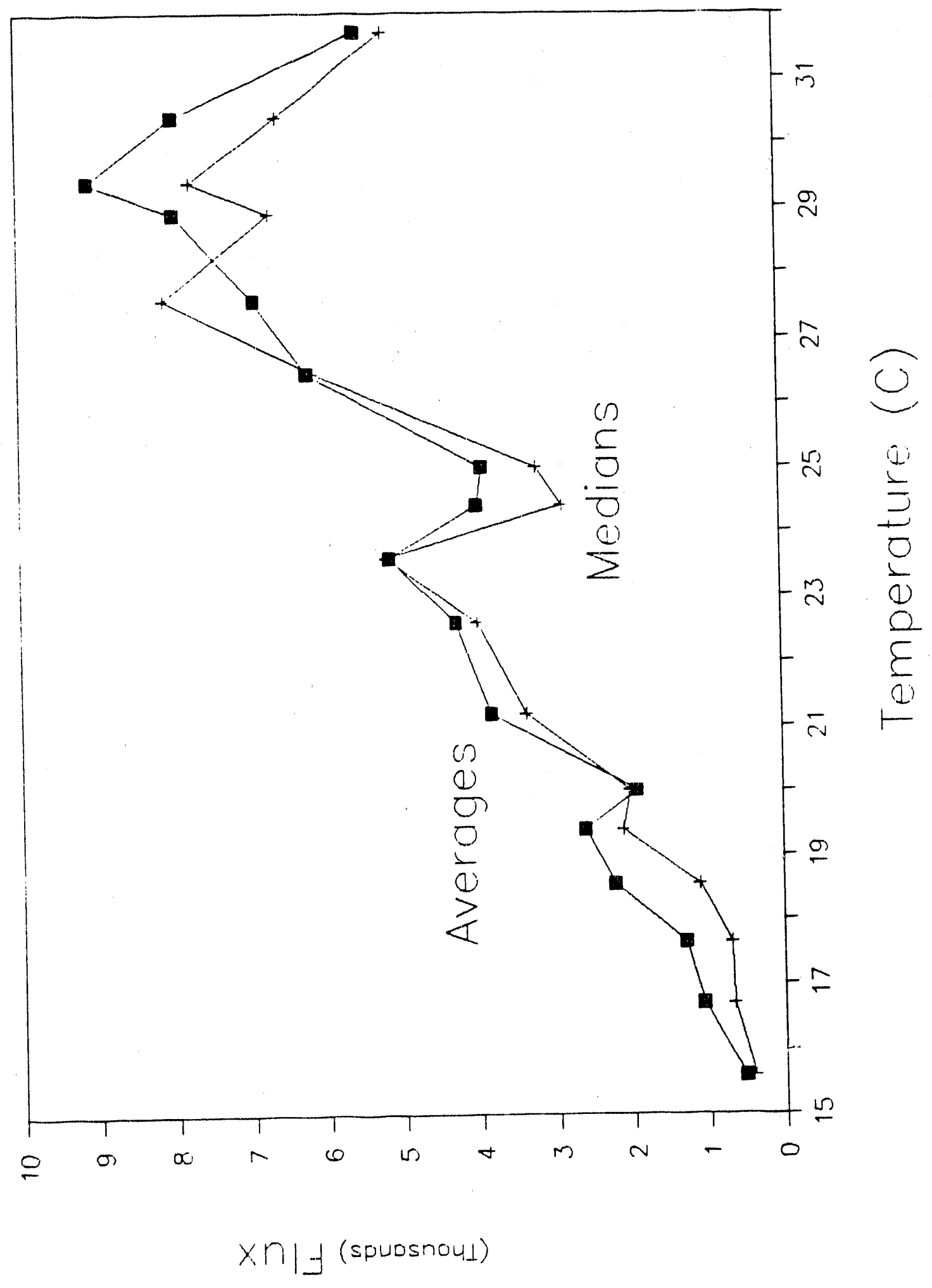




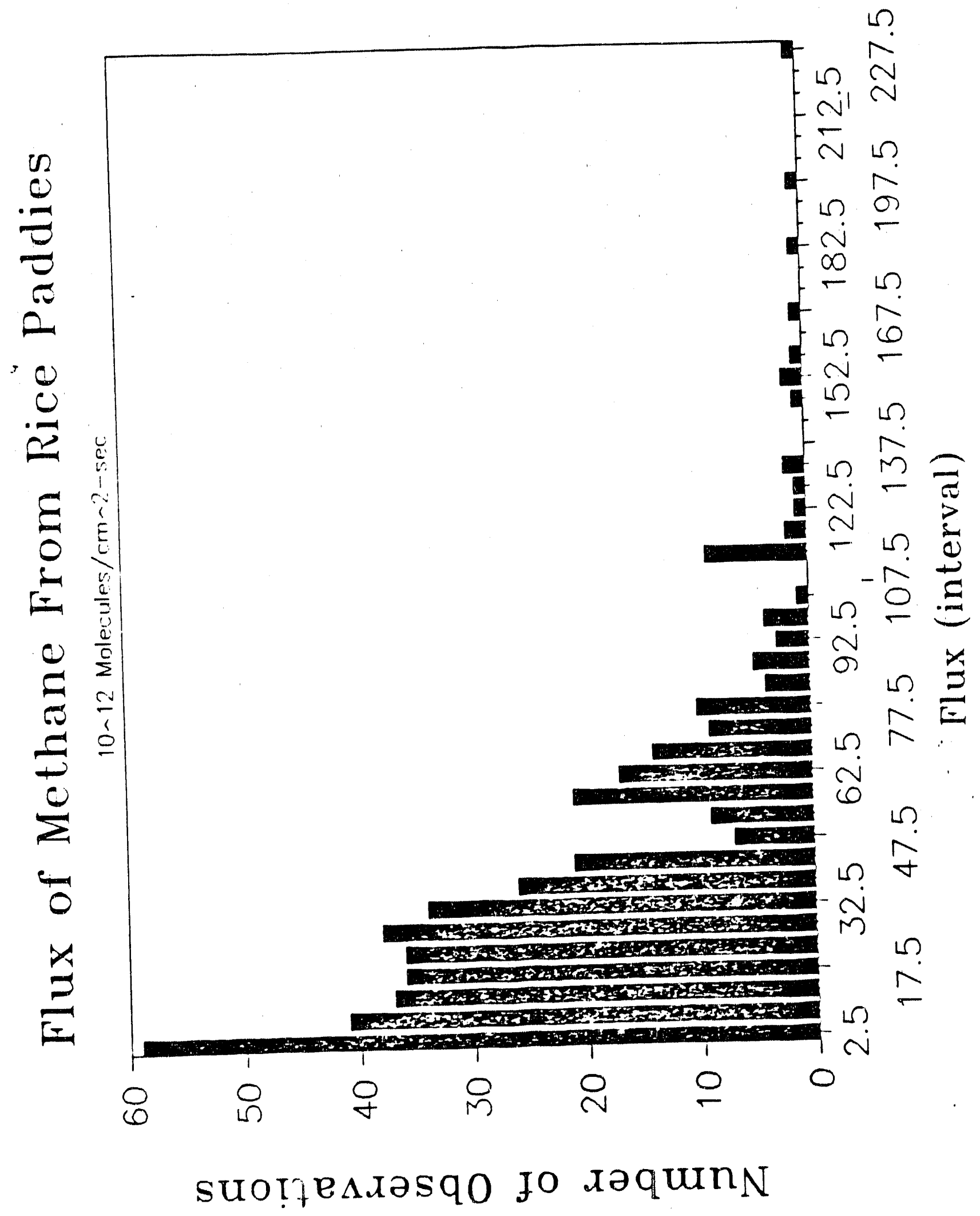




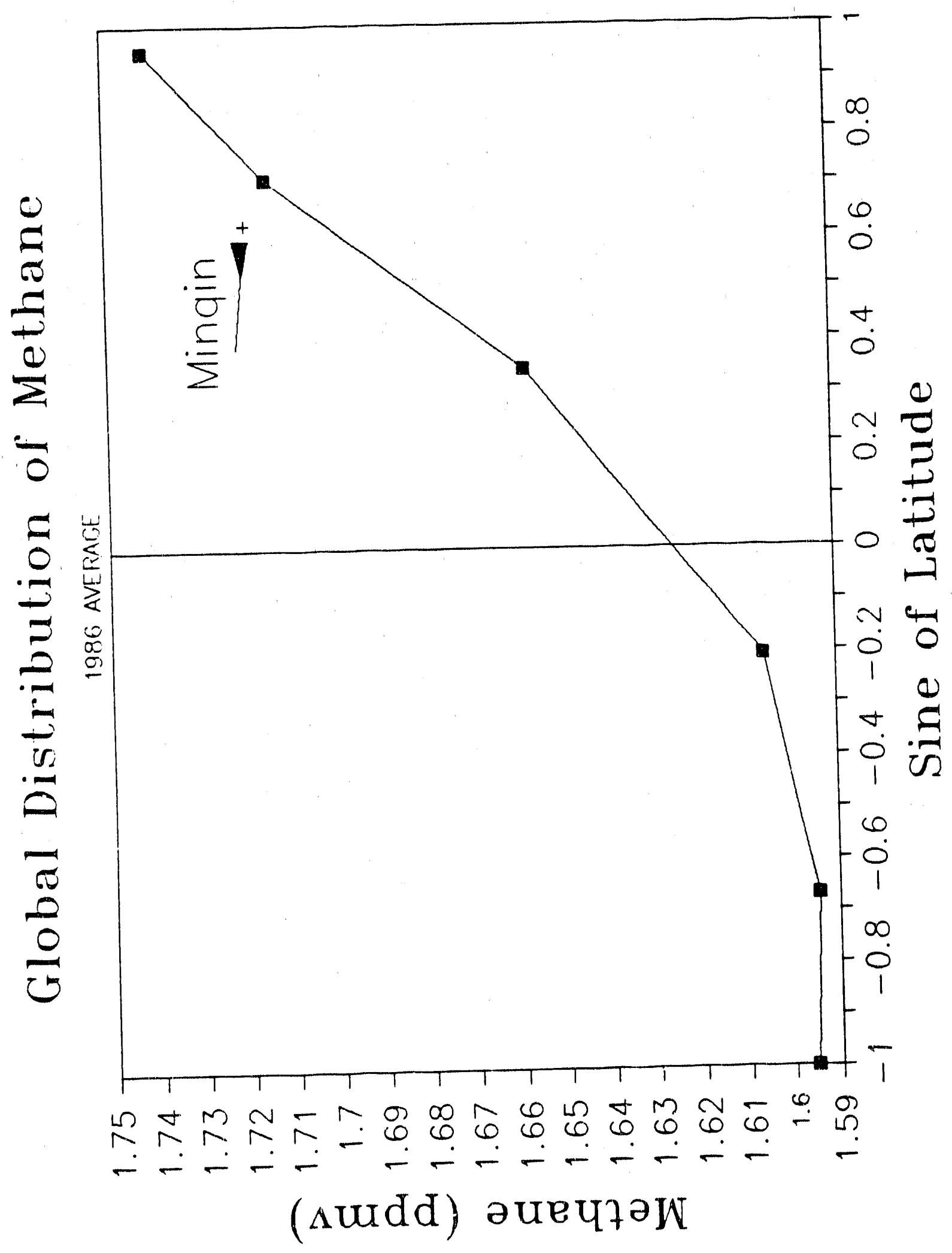




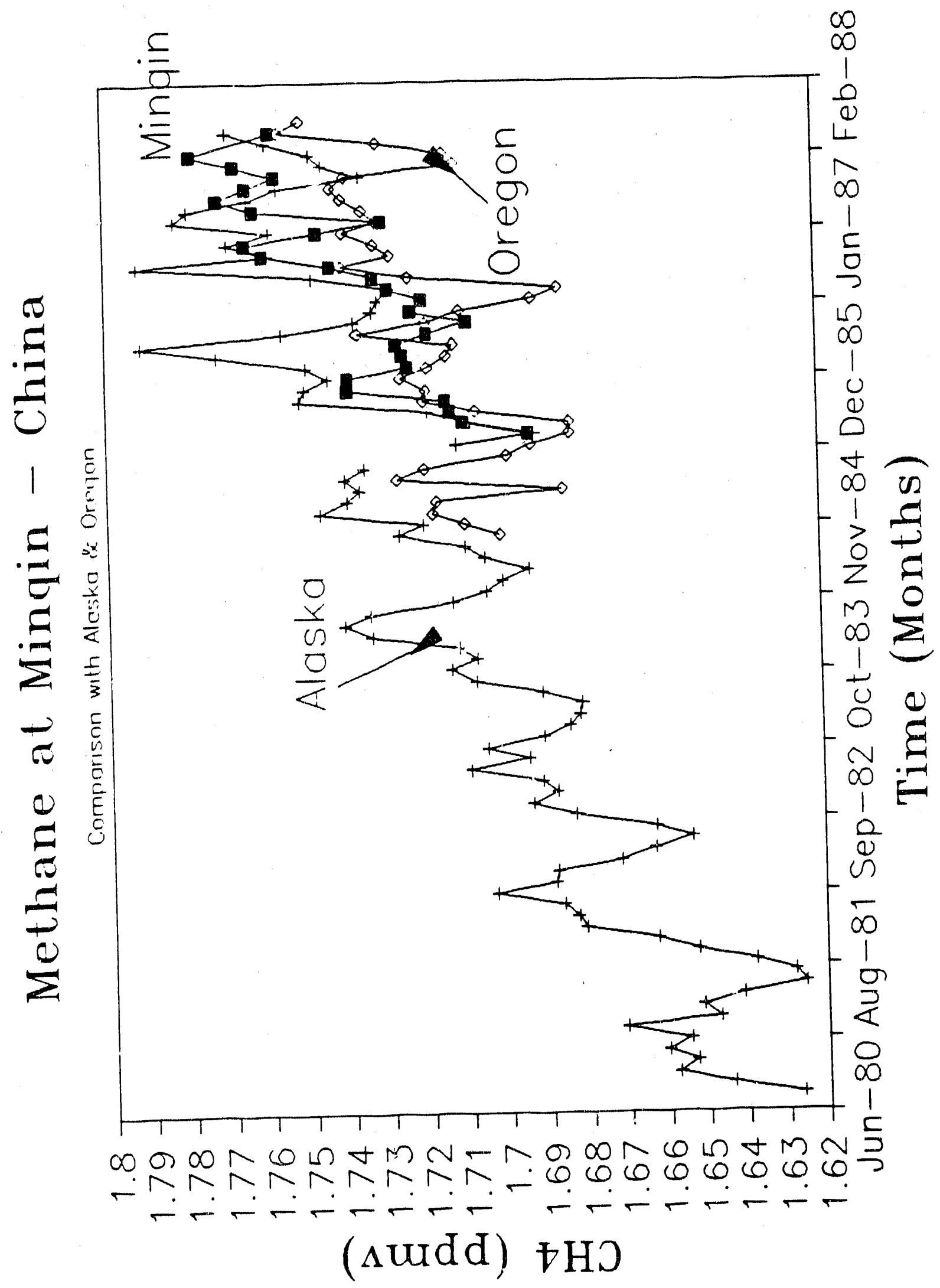




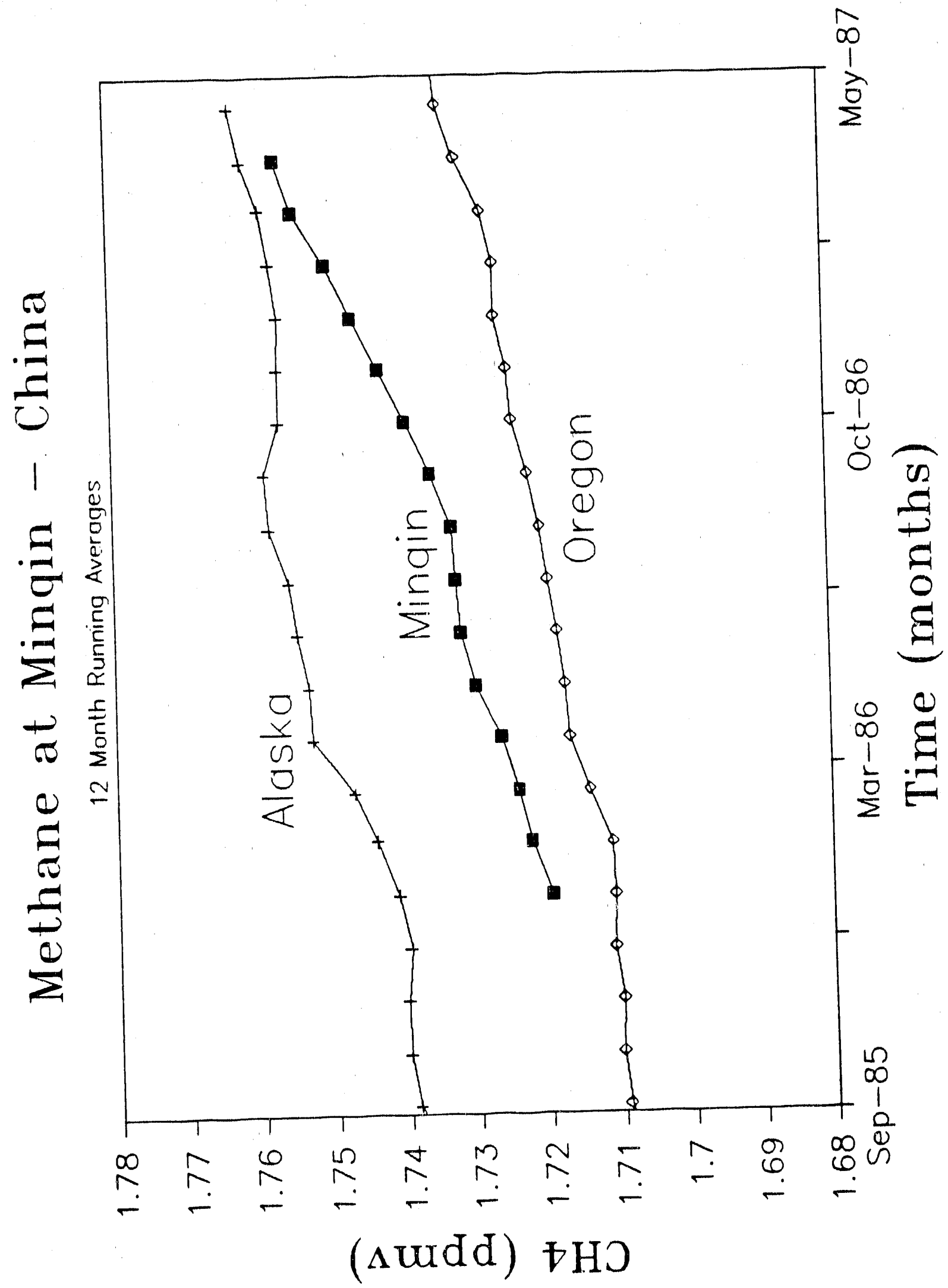




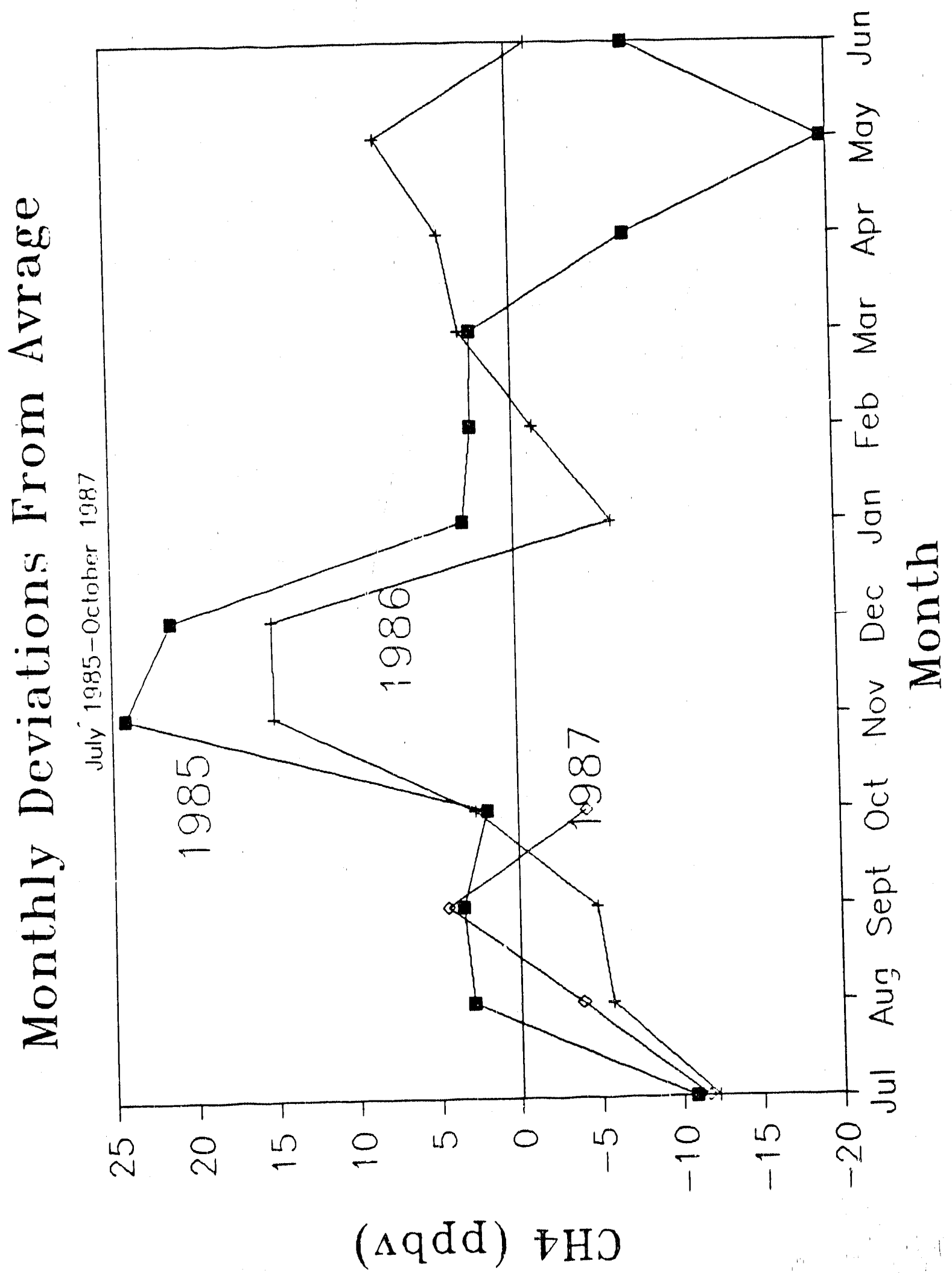




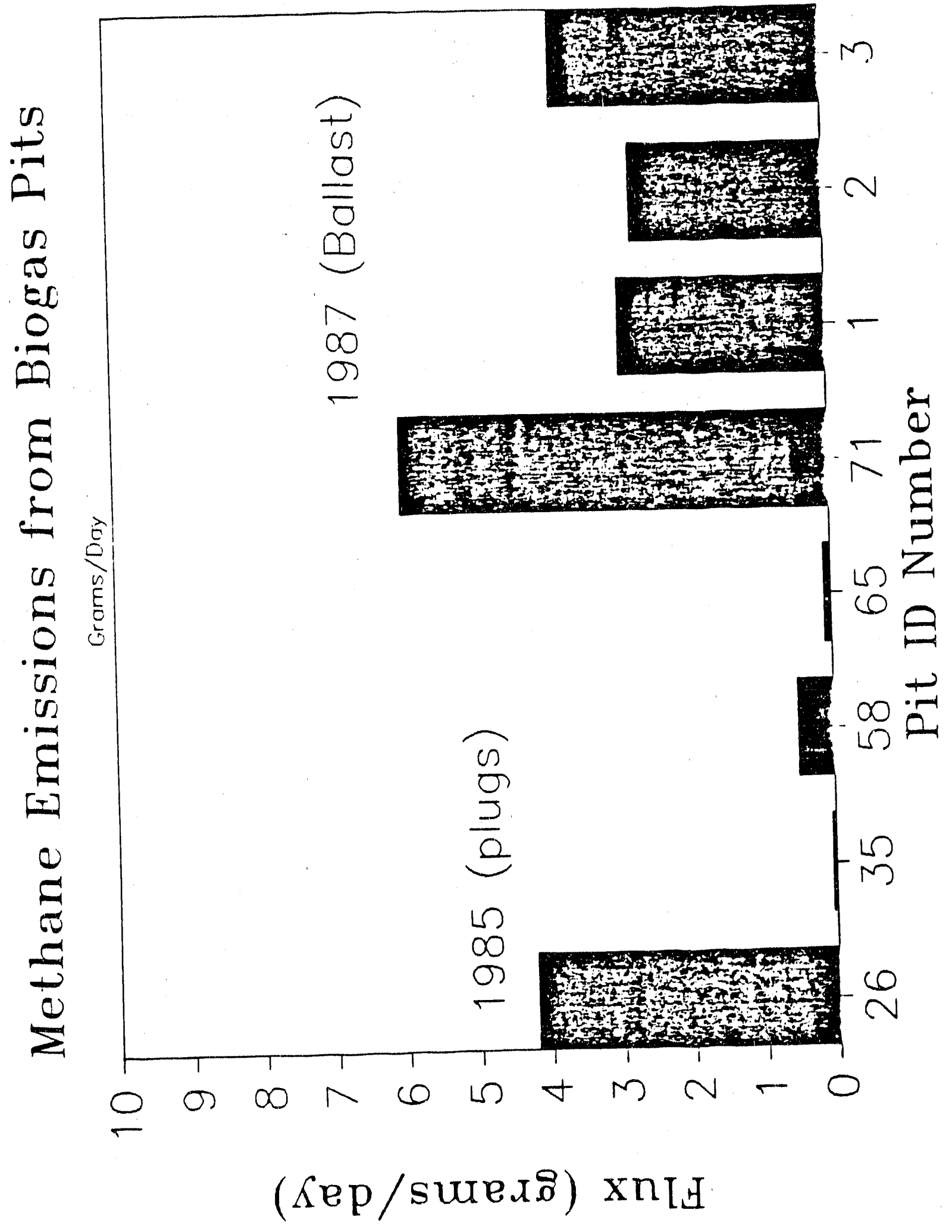




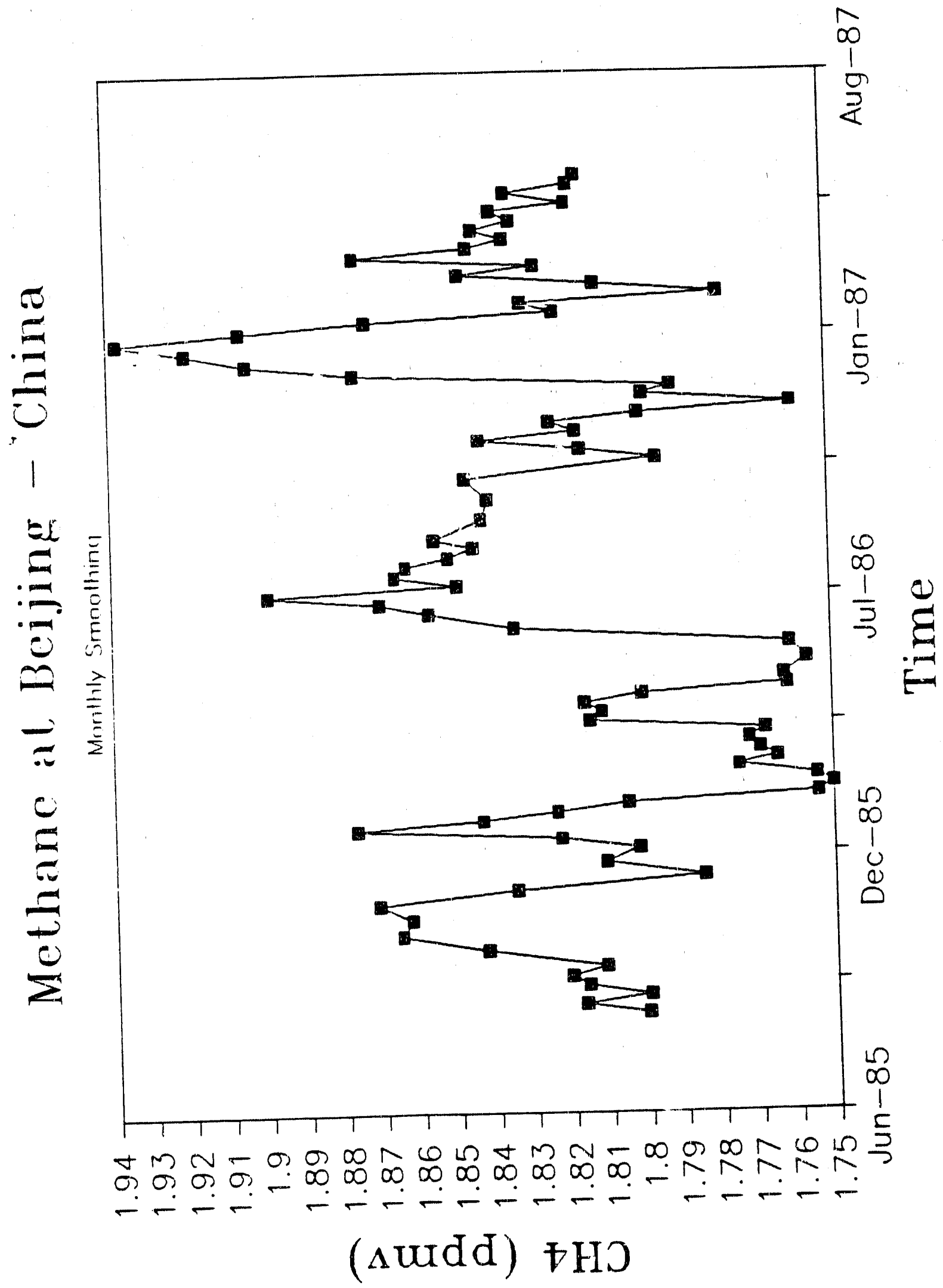


Atmospheric Methane: Recent Global Trends

.A.K.Khalil

F. A. Rasmussen

Institute of Atmospheric sciences

oregon Graduate? Center

Beaverton, Oregor 97006 USA

(November 1988)

submitted to science 


\begin{abstract}
:
We report the globally averaged concentrations of atmospheric methane for every month of the past 8 years. This intensive record shows that methane increased at an average rate of $17.7 \pm 0.4$ $\mathrm{ppbv} / \mathrm{yr}$ or about $1.08 \pm 0.03 \% / \mathrm{yr}$ over 8 yeurs. The trend of methane has not been constan: according to our record but has varied between $12+2$ and $27 \pm 2 \mathrm{ppbv} / \mathrm{yr}$ over 2 -year periods after seasonal variations are taken into account. The causes of these inter-annual variations are not known. We also show that the total mass of methane in the earth's atmosphere undergoes seasonal variations with highest levils during northern hemisphere winters aidd lowest levels in the slminers. After the main features of the record are taken into account, residual random fluctuations remain, which have a variability of only 2 ppbv or $0.13 \%$ of the mean concentrations. Uncertainties in our estimates are reported as $90 \%$ confidence limits.
\end{abstract}

There is no longer any doubt that the concentration os atmospheric methane is increasing (Rasmussen \& Khalil, 1980; Fraser et al., 1981; Blake et al., 1982; Khalil \& Rasmussen, 1983; Rinsland et al., 1985; Blake \& Rowland, 1988). If this trend continues, high levers of methane may, in the future, cause global warming and r.ffect the cycles of carbon monoxide ard ozone in the troposphere rncl of water vapor and ozone in tre stratosphere. The purpose of our paper is to show how methane has changed over the last eight years.

Euring the past eight years we have taken systematic atmospheric measurements of methane at six locations spread out in la!itudes from the arctic to the antarctic and referenced against a single calibration standard. Although we began in late 1978, it was not until september 1980 that samples started coming from all six locations. Flask samples were collected in triplicate every week at Barisow, Aliska $\left(72^{\circ} \mathrm{N}\right)$, Cape Meares, oregon $\left(45^{\circ} \mathrm{N}\right)$, Cape Kumukahi and Mauna Loa, Hawail $\left(20^{\circ} \mathrm{N}\right)$, Samoa $\left(12^{\circ} \mathrm{S}\right)$, Cape Grim, Tasmania $\left(42^{\circ} \mathrm{S}\right)$, and in antarctica mostly at the south pole $\left(90^{\circ} \mathrm{S}\right)$. These sites span the major regions of the earth where concentrations of 
trace gases change with latitude including the polar, middle, and tropical l'atitudes of both hemispheres. At Cape Meares we have also used automated instruments to measure methane up to 70 times per day. The resulting data, consisting of some 6,000 individual flask sampling measurements and 100,000 automated measurements at Cape Meares, are perhaps the most lietailed long-term record available.

Data from some sites required special treatment before inclusion in the global average. For cape Meares, data from both automated measurements and flask samples were combined. In Hawaii we noted that concentrations at Mauna Loa were on average about $0.9 \%$ lower than at nearby Cape Kumukahi. Mauna Loa is generally above the planetary boundary layer, so the concentrations of many trace gases are somewhat less than at cape Kumukahi, which is at sea level. We therefore adjusted all measurements taken at Mauna Loa upwards by $0.9 \%$. Whenever there were measurements at both the Hawaiian sites we took the average of the cape Kumukahi and the adjusted concentrations at Mauna Loa to obtain the ground level concentrations at Hawai. Measurements for Antarctica include data from Mawson reported by Fraser et al. (2986) and our measurements taken at the south pole. Concentrations over Antarctica were nearly the same as at cape Grim, Tasmania. Once in a while there were insufficient data to obtain a monthly average at one site or another. These gaps were filled by interpolation.

We used the weekly samples to calculate average monthly concentrations at each site. We then formed an average for the northern $(C n)$ and southern (Cs) hemispheres, and the global average (C) as in Equation 1.

$c_{n}=\int_{0}^{1} c(\phi) d \sin \phi$

$c_{s}=\int_{-1}^{0} C(\phi)$ a $\sin \phi$

$c=\frac{1}{2}\left(c_{n}+c_{s}\right)$ 
where $\phi$ 'is the latitude. The global monthly average concentrations are shown in Figure 1. The increasing trend is evident. The globally averaged concentration of methane increased from about $1560 \mathrm{ppbv}$ in september 1980 to 1710 ppbv eight years later in october 1988. This amounts to an additional 350 million metric tons of methane in the atnosphere now, compared with the amount eight years ago.

Although the increase is fairly steady, there are other features in the data that cannot be found in reccrds with less frequent measurements. We decomposed the time series into five components:

$\begin{aligned} c=C_{0} & +b t+\text { Annual Cycle } \\ & + \text { Inter Annuall Variability + Residuals }\end{aligned}$

where $C_{0}$ is the concentration when measurements began and $b$ is the rate of increase (ppbv/yr). The inter-annual variability is defined as aperiodic changes of known or unknown origins. The residuals are the remaining random variability. The methods for separating the various components of the time series have been discussed elsewhere (Khalil \& Rasmussen, 1986; 1988). The results of this decomposition are shown in Figure 2 .

The seasonal variation or the annual cycle shows that, aside from the increasing trend, the earth's atmosphere contains more methane during our winters (October to December) than during summers (June to August); see also steele et al. (1987). The average difference between maximum and minimum concentrations is about $10 \mathrm{ppbv}$, although in some years the difference could be twice as large or considerably smaller. The annual cycles of concentrations are driven by atmospheric chemistry, particularly the seasonal variations of hydroxyl radicals, which remove methane from the atmosphere, and also by the seasonal variations in the biological 
activity that produces methane. Consequently, the annual cycles are reversed in the two hemisphere. There is about $5.4 \pm 0.1 \%$ more methane in the northern hemisphere compared to the southern hemisphere, and the amplitude of the cycles is also proportionately greater in the northern hemisphere. So when methane is at its maximum in the northern hemisphere, the high concentration is not balanced by the minimum in the southern hemisphere.

We estimated the increasing trend after subtracting the annual variations from the data and found it to be $17.7 \pm 0.4 \mathrm{ppbv} / \mathrm{yr}$ (= b) and $\mathrm{c}_{0}=1528 \pm 1 \mathrm{ppbv}$.

The inter-annual variations are the remaining systematic changes in the data when the annual cycles are subtracted. Here they range from -6 ppbv to +8 ppbv. These variations are caused by a combination of atmospheric variability, variations of sources and sinks, and by variations in laboratory instruments and calibration standards. Some time back the analysis of the detailed data from Cape Meares suggested that there was a large reduction in methane concentration around the time of the major $E I$ Nino of 1982-83 Khalil \& Rasmussen, 1986). Subsequent measurements prompted a reanalysis of the data, which now show that much of the effect was caused by a calibration error in the early part of the data record. Before the El Nino, concentrations of methane were greater at Cape Meares than at Barrow, a feature also shared by several other trace gases. However, measurements taken at Cape Meares for some years after the El Nino were somewhat higher but remained below the levels at Barrow. This peculiar behavior was traced to a mistake in recording the concentration of methane in an early calibration standard. When the calibration correction was made, methane at Cape Meares remained only slightly less during the period of $E l$ Nino compared with the times before and after, and the concentration at Barrow is almost always higher than at cape Meares throughout the record. The present data shown in Figure 1 include 
the adjustment for the calibration error. El Nino events, therefore,' do not appear to have the major effect on the methane cycle we once thought they did. This incident demonstrates the difficulty in interpreting inter-annual variations in short records when there has not been enough time for events to recur. Even though in the present record. (Figure 2) there are minor (< $0.5 \%$ ) inter-annual variations, it is not certain whether they represent the atmospheric behavior of methane or the variations of calibration standards or instruments.

Regardless of what causes inter-annual variations, we think of them as affecting the trends of methane over short times as shown in Figure 3. We calculated the rates of change of methane over every 2-year contiguous period after subtracting the seasonal variations. Lowest rate of increase was about $12 \pm 2$ ppbv/yr and highest was $27 \pm 2 \mathrm{ppbv} / \mathrm{yr}$. The results show that while measurements taken over short times may provide evidence of increasing trends, the rates are not necessarily representative of long-term increases. In our case the inter-annual variations, since they include both decreases and increases, do not affect the long term trend. If we subtract both the seasonal variations and the inter-annual variations from the data and then estimate the trend, it turns out to be $17.7 \pm 0.2 \mathrm{ppbv} / \mathrm{yr}$.

Finally, after the inter-annual variations are subtracted from the data, random fluctuations remain. In this case the residuals are normally distributed with mean value near 0 and a standard deviation of $2 \mathrm{ppbv}$. The standard deviation of the inter-annual variations and the residuals together is $5.8 \mathrm{ppbv}$.

Acknowledgements: We thank the National Oceanic and Atmospheric Administration's Global Monitoring for Climatic Change (NOAA/GMCC) for collecting samples at Barrow, Samoa, Mauna Loa, and the :iouth Pole. We also thank Don stearns for laboratory work, A.J.Crawford 
for field work, and Paul Turner for data management. This work was supported in part by the National science Foundation (ATM-8414020, DPP-8207470, DPP-8717023) and the Department of Energy (DE-FG0685ER6031). Additional support was provided by the Biospherics Research Corporation and the Andarz Co.

References:

Blake, D.R., E.W.Meyer, S.C.Tyler, Y.Makide, D.C.Montague, and F.S.Rowland (1982). Global increase in atmospheric methane concentrations between 1978 and 1980. Geophys. Res. Lett. 9, 477480 .

Blake, D.R. and F.S.Rowland (1988). Science

Fraser, P.J., M.A.K.Khalil, R.A.Rasmussen, and A.J.Crawford (1981). Trends of atmospheric methane in the southern hemisphere. Geophys. Res. Lett. 8, 1063-1066.

Fraser, P.J., P.Hyson, R.A.Rasmussen, A.J.Crawford, and M.A.K.Khalil (1986). Methane, carbon monoxide and methylchloroform in the southern hemisphere. J. Atmos. Chem. 4 3-42.

Khalil, M.A.K., and R.A.Rasmussen (1986). Interannual variability of atmospheric methane: Possible effects of the El Nino - southern oscillation, Science 232 56-58.

Khalil, M.A.K., and R.A.Rasmussen (1988). Atmospheric trace gases: Mathematical methods for the analysis of time series (in preparation).

Khalil, M.A.K., and R.A.Rasmussen (1983). Sources, sinks and seasonal cycles of atmospheric methane. J. Geophys. Res. 88 51315144 . 
Rasmussen, R.A., and M.A.K.Khalil (1981). Atmospheric methane: Trends and seasonal cycles. J. Geophys. Res. 86 9826-9832.

Rinsland, C.P., J.S.Levine, and T. Miles (1985). Concentration of methane in the troposphere deduced from 1951 infrared solar spectra, Nature 318, 245-249.

Steele, L.P., P.J.Fraser, R.A.Rasmussen, M.A.K.Khalil, T.J.Conway, A.J.Crawford, R.H.Gammon, K.A.Masarie, and K.W.Thoning (1987). The global distribution of methane in the troposphere, I. Atmos. Chem. 5 $125-.271$. 
Figure Captions:

Figure 1. The average global concentrations of methane spanning every month of the 8 years between september 1980 and october 1988 . The average concentrations are estimated from measurements taken at Barrow, Alaska, in the arctic; Cape Meares in oregon; two sites in Hawaii; Samoa; cape Grim in Tasmania; and the Antarctic incluaing the south fole.

Figure 2. The concentrations of methane shown in Figure 1 are decomposed into several additive components. Aside form the increasing trend the other components are (a) Seasonal cycles, (b) Inter-annual variations, and (c) Random fluctuations.

Figure 3. The trends over each successive 2-year period and the $90 \%$ confidence limits plotted in the middle of the time period over which the trend is calculated. The figure shows that the rate of increase is not constant, and trends over short times may not reflect long-term tendencies. 
F'IGURE 1

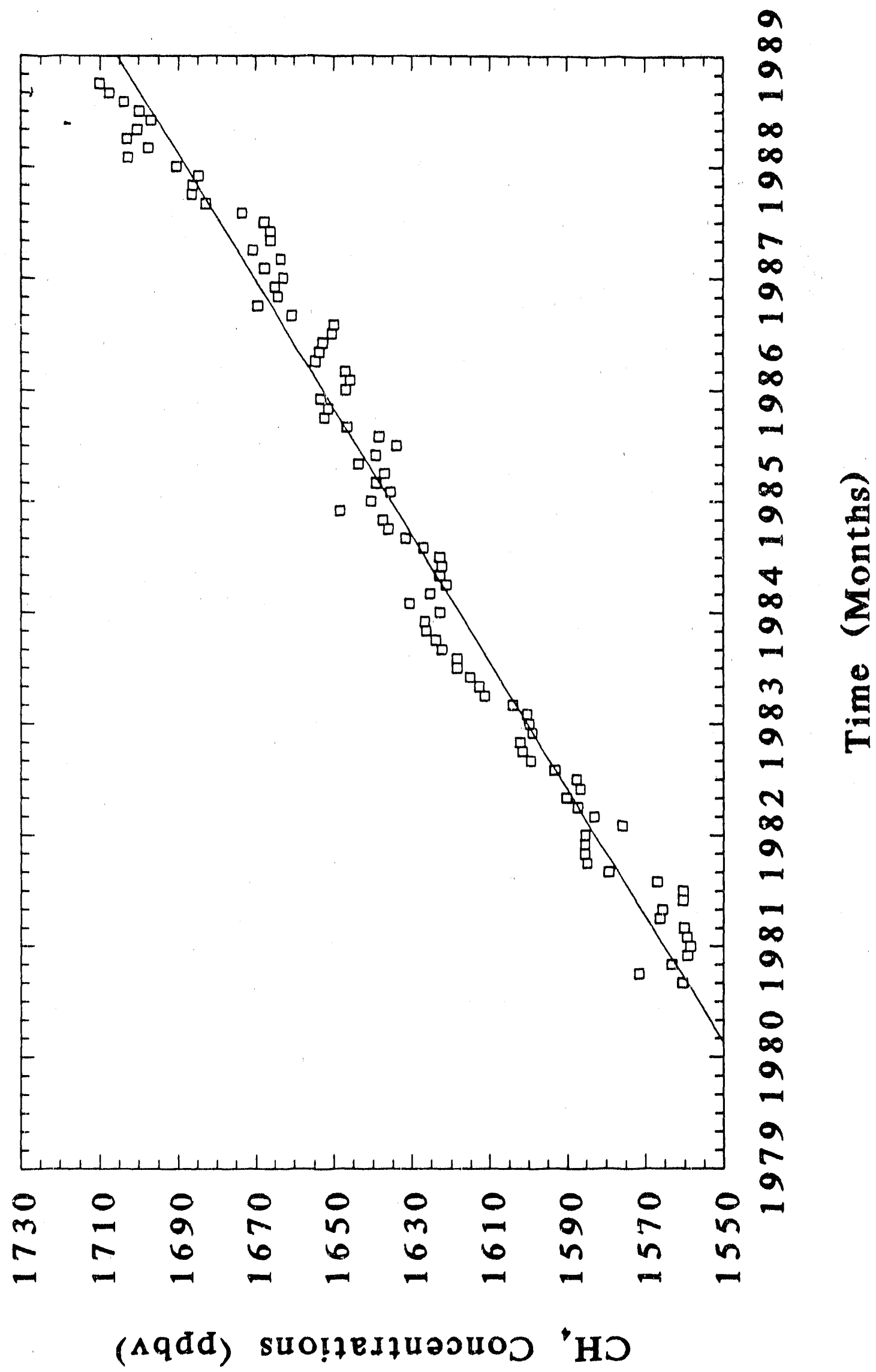


FIGURE 2
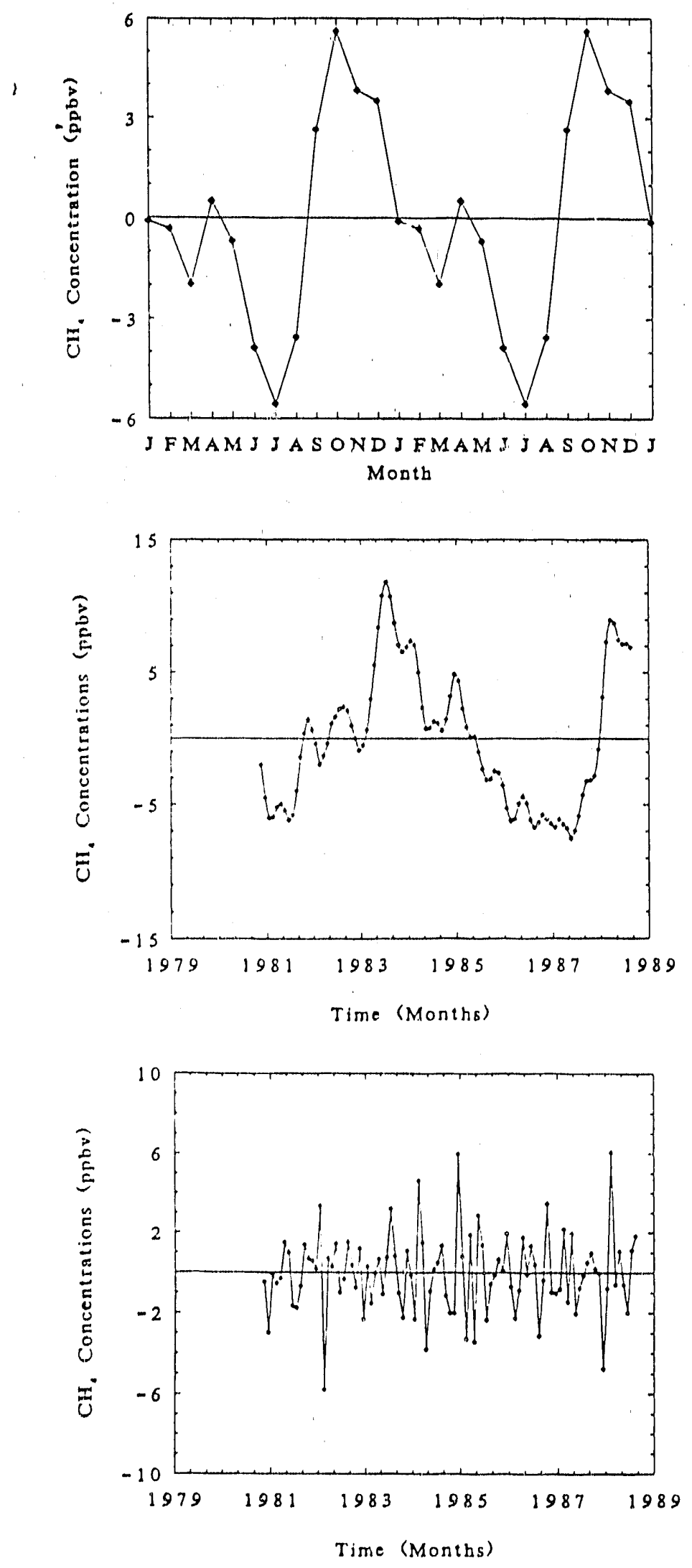


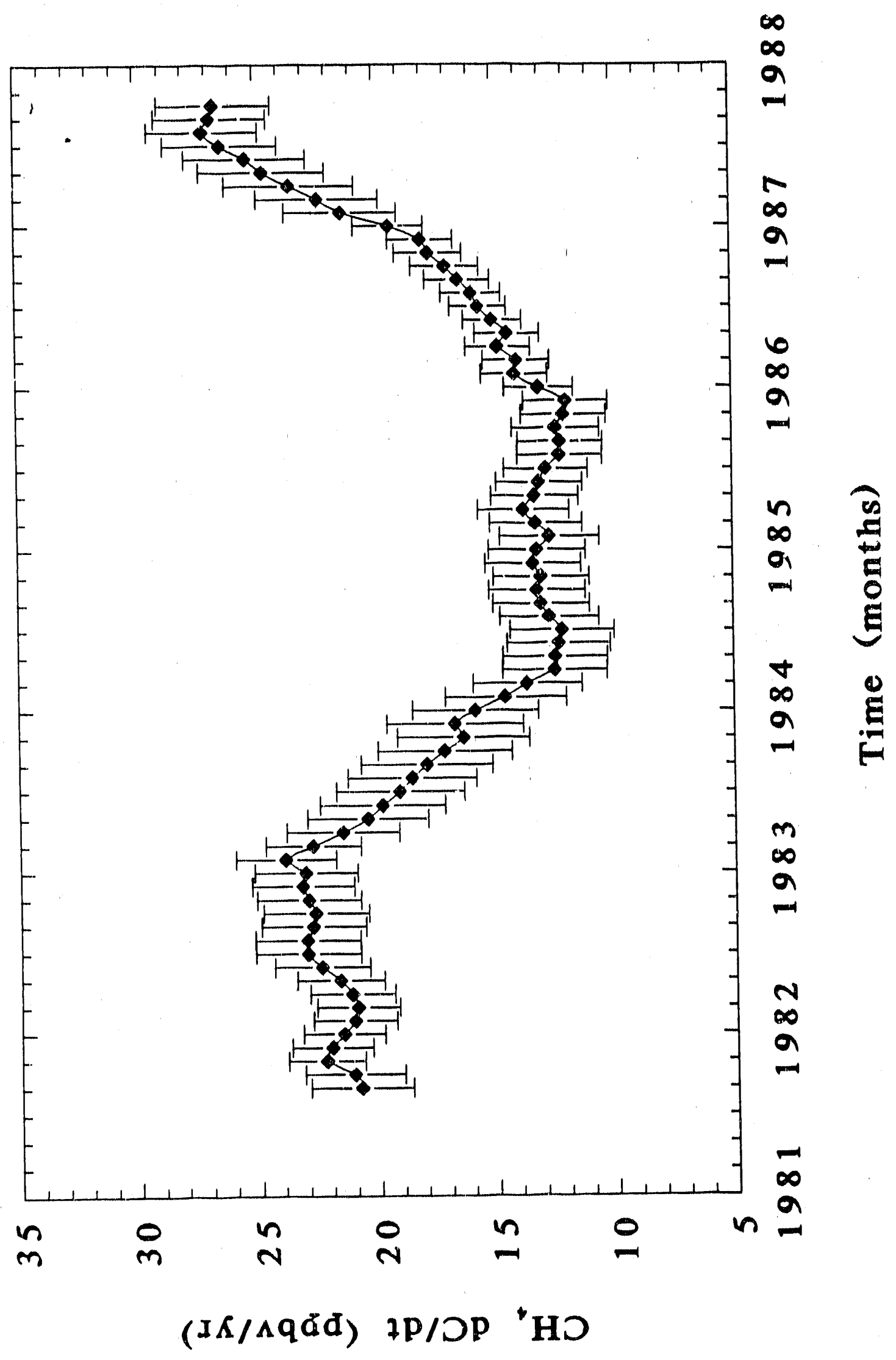



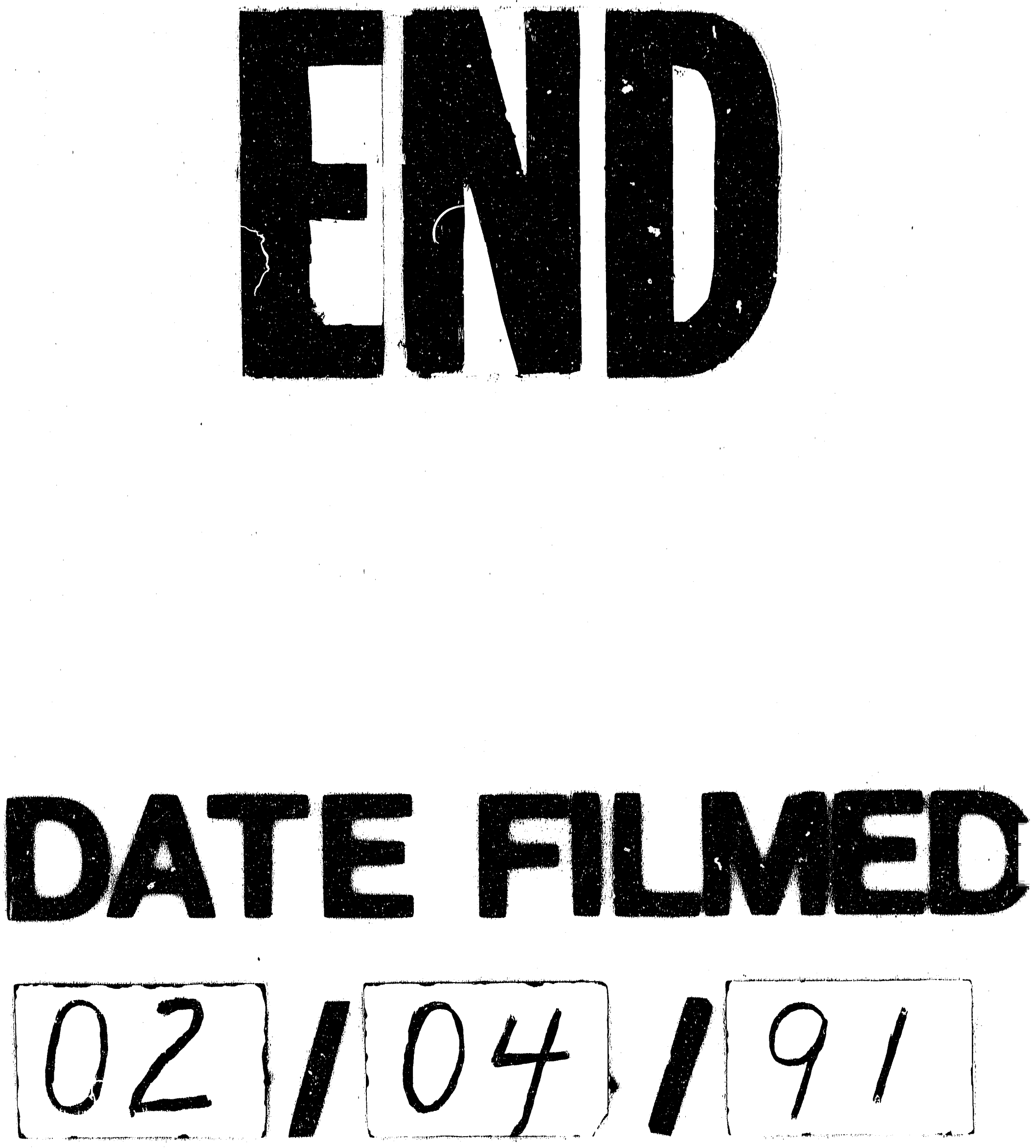